\title{
Los vínculos económicos entre Callao, Arica y Valparaíso durante la Confederación Peruano- Boliviana 1836-1839 ${ }^{1}$
}

\section{Economic links among Callao, Arica and Valparaiso during the Bolivian-Peruvian Confederation 1836- 1839}

Cristina Mazzeo

\section{Resumen}

El objetivo es analizar la relación entre los puertos principales de Valparaíso y el Callao con los puertos intermedios del sur andino durante la Confederación Peruano-Boliviana. Se demuestra cómo a pesar de los conflictos políticos desatados por la guerra contra la Confederación, el comercio llevado a cabo por importantes empresas mercantiles extranjeras instaladas en Valparaíso se relacionó con los puertos de Arica, Islay y Cobija, que actuaron como conectores con el gran comercio internacional. El nuevo grupo de comerciantes creó una red

1 Este trabajo fue financiado por la Dirección de Gestión de la Investigación de la Pontificia Universidad Católica del Perú (PUCP) a través de la subvención DGI - 1015-1-0026 con el título Conflictividad política, unidad económica, los puertos del Pacífico Sur: Arica, Islay y Quilca 1820-1840. Contacto: cmazzeo@pucp.pe 
mercantil muy vinculada en la región. Tomando como base la documentación de las aduanas de Bolivia, Chile y Perú se aborda hasta qué punto la competencia de intereses entre el puerto de Arica y Cobija fue una de las razones que provocó la guerra contra la Confederación.

Palabras clave: Confederación Peruano-Boliviana, comercio marítimo, Valparaíso, Callao, Arica

\section{Abstract}

The objective is to analyze the relationship among the main ports of Valparaiso and Callao with the intermediate ports of the southern Andes during the Bolivian-Peruvian Confederation. It shows how despite the political conflicts unleashed by the war against the Confederation, the trade carried out by important foreign mercantile companies installed in Valparaiso connected the ports of Arica, Islay and Cobija, which acted as links with the great international trade. The new group of merchants created a closely linked merchant network in the region. Based on the documentation of Bolivia, Chile and Peru customs, it addresses the extent to which the competition of interests between the port of Arica and Cobija was one of the reasons for the war against the Confederation.

Key words: Bolivian-Peruvian Confederation, maritime trade, Valparaíso, Callao, Arica, Islay, Cobija.

\section{Introducción}

La región sur andina que incluye los puertos de Arica, Islay y Quilca, Cobija, fue una de las zonas más conflictivas en el 
siglo XIX, al punto que lograron enfrenar a tres países en una guerra continental debido al deseo de controlar la región por sus riquezas naturales. Ya en el siglo XVIII, esta región conformaba un núcleo económico cuyo centro de irradiación era Potosí. ${ }^{2}$ Luego de la independencia, si bien la organización política dio lugar a diferentes países, la economía y la vinculación de los espacios marítimos y terrestres siguió funcionando más allá de los conflictos bélicos. Arica, a comienzos del siglo XIX, era el puerto de entrada hacia las ciudades de Arequipa, Puno, La Paz, Potosí, Cusco, mientras que Quilca fue un puerto menor que no estaba habilitado para introducir mercaderías en el sur andino. El puerto de Islay, el principal de Arequipa, y el de Cobija fueron usufructuados por la Confederación Peruano-Boliviana, que a su vez contaba con la hegemonía del sistema monetario, el peso feble, una moneda de baja ley lanzada a la circulación por el general Santa Cruz (Manrique, 1995, p. 32).

Desde el punto de vista político-regional, las independencias en América Latina dieron lugar a un marcado regionalismo (Cavieres, 2007, pp. 17-39), que generó el surgimiento de caudillos en el sur del continente. En otras regiones, un fuerte centralismo impidió la fracción del país, no obstante, también se vivió la rivalidad regional. En el Perú, la rivalidad entre las ciudades de Lima, Arequipa y Cusco se hizo sentir desde mucho tiempo antes. En Bolivia, la rivalidad regional se presentó entre la ciudad de Chuquisaca y la Paz, y estaba más vinculada a cuestiones mercantiles con el Bajo Perú y su proyección hacia

2 Una investigación anterior "La interconexión de los puertos del Pacifico y el puerto de Arica entre 1820 y 1830 " da cuenta de la importancia de este puerto en el sur andino, como eje articulador de la economía regional. El proyecto de investigación fue financiado por la DGI de la PUCP en el 2014. 
el Pacífico (Parkerson, 1984, p. 18). Estas diferencias no pudieron ser soslayadas con la creación de los Estados-nación y las marcaciones territoriales aún muy endebles en ese tiempo.

Por esa razón, la separación de Bolivia y el Perú no significó una desarticulación del circuito económico del sur andino, más bien se mantuvo y el puerto de Arica tuvo una importancia singular como puerta de entrada a las ciudades de dicha región. Frente al conflicto político desatado con la Confederación se evidenció un conflicto regional fuerte, pero a la vez cierta integración económica a través de los vínculos mercantiles que los nuevos mercaderes extranjeros extendieron en la zona, que crearon nuevas redes de comercio con nuevos actores.

La historiografía sobre la Confederación, tanto chilena como peruana y boliviana, ha considerado a esta como negativa para la región, con algunas excepciones. Los trabajos realizados desde el punto de vista político se han basado en la rivalidad entre Santa Cruz, Gamarra y Portales (Walker, 2004; Cavieres, 2007; Serrano, 2013). Desde el punto de vista económico, Gootemberg (1997, pp. 67-68) plantea la rivalidad entre un norte proteccionista y un sur liberal, tesis a la cual se adhiere también Contreras, quienes, a su vez, ven la guerra desatada como una "guerra de secesión en los Andes" haciendo alusión a la guerra civil entre el norte y el sur en los Estados Unidos 200 (Contreras, 2000, p. 101). Zapata considera que la oposición a la Confederación se debió a los caudillos regionales y a las alianzas con sus pares para ejercer el poder más allá de posiciones políticas (2009, p. 94). En la historiografía boliviana, destacan los trabajos de Parkenson (1984); Baldivia (1919), Cajías (1975) y Aillón (2009), quienes se concentran en el conflicto suscitado por la separación de Bolivia y el Perú y enfatizan la rivalidad entre los puertos de Cobija y Arica. En la histo- 
riografía chilena, los trabajos editados por Cavieres (2007), Rosenblitt (2013) y Serrano (2013) tratan la importancia del conflicto a partir de lo regional, la identidad y la unidad entre Bolivia y el Perú. Cajías argumenta que mientras Bolivia gozaba de prosperidad y tranquilidad en 1830, la situación política era caótica en el Perú, por lo que inmiscuirse en los asuntos peruanos, como hizo Santa Cruz, no fue beneficioso: "Bolivia se desgastó en una guerra que prácticamente pagó con su tesoro" (1975, pp. 155-156).

La hipótesis de esta investigación es que la condición de los puertos intermedios, en especial Arica, Cobija e Islay, jugó un papel importante en el conflicto bélico, no solo por el ingreso de mercancías al sur andino, sino por su posición estratégica entre Valparaíso y el Callao. Además, el dominio de dichos puertos fue una de las variables que agudizó la rivalidad ente Chile, Bolivia y Perú, y generó la oposición a la Confederación. Santa Cruz decía en la Asamblea de Sicuani (17 de marzo de 1836), que le confirió el título de Protector, que se le debía adjudicar Tacna y Arica a Bolivia "ya sea por vía de indemnización de los gastos que le había costado la intervención (en la guerra civil contra Salaverry) o lo que es más seguro por ambos motivos; porque si no pillamos esta tajada no veo cuándo ni cómo se puedan resarcir nuestros desembolsos" (Querejazu Calvo, 1996, p. 111). Evidentemente, esto traía cierta inquietud a los limeños, como lo hace notar Santa Cruz en una carta del 31 de abril de 1836 a su vicepresidente Calvo: "parece que en Lima ha causado alguna alarma la resolución de Sicuani entre los nacionalistas que temen que solo queremos formar un Estado vecino para quitarle Arica..." (Querejazu Calvo, 1996, p. 127). Islay sería el puerto de ingreso de productos para Arequipa, mientras que Quilca se comportaría como un puerto menor. En cuanto a Cobija, evidentemente sufrió las 
vicisitudes de la guerra, dado que fue destruido por Salaverry en 1836 (Cajías, 1975, p. 155). Por otro lado, Arica siguió siendo el puerto de tránsito en la conexión del puerto de Valparaíso con el Callao, que a pesar de los conflictos bélicos, se mantuvo como la conexión más importante para los comerciantes extranjeros instalados en Valparaíso, donde funcionaba el principal centro de distribución de mercancías a lo largo del Pacífico por su política de libre comercio y de almacenes libres implementada por el ministro Rengifo en la década de 1830 (Collier y Sater, 1999, p. 64).

\section{Antecedentes históricos}

La independencia de Bolivia declarada en 1825 no se consolidó sino hasta la caída de la Confederación Peruano-Boliviana en 1842. La división territorial llevada a cabo por Bolívar era muy débil, al punto que en la asamblea realizada en Chuquisaca hubo diferentes facciones, unas a favor de la unión con el Bajo Perú, otra con Argentina y otra que promovía la autonomía, que fue la que ganó y determinó la separación, "ni con Lima ni con Buenos Aires" como diría luego el historiador boliviano José Luis Roca (2011). La unión con el Perú tenía varios factores a su favor, como sostiene Basadre: conformaban una comunidad de razas, pueblos e intereses económicos y tenían una historia común (1999, pp. 1-14).

Por otro lado, existía la intención de unión por parte de la población. La rebelión de Salaverry en $1835-1836,{ }^{3}$ que puso al país al borde de la anarquía y de la guerra, motivó que los

3 Durante el gobierno de Orbegoso se sublevó Felipe Salaverry en defensa de los intereses proteccionistas que propiciaban las ciudades del norte del Perú (Contreras y Cueto, 2000, p. 101). 
vecinos de Moquegua, Tacna, Arica y Locumba solicitaran la anexión a Bolivia. Estos pueblos sentían que la unión con el Perú había sido violada y por tanto haciendo uso del derecho de gentes querían unirse a Bolivia:

Nuestras relaciones comerciales están circunscritas a los pueblos limítrofes de la Nación Boliviana; allá residen nuestras conveniencias, y si no aprovechamos la oportunidad de que sean permanentes y no se expongan a los diarios vaivenes de que han sido víctimas renunciamos para siempre a los consuelos de conseguir la prosperidad de que se nos niega por otros medios". (Baldivia, 1919, p. 40).

Esto dio como resultado la declaratoria del acta de Tacna, en 1836, por la que se separaba de Lima teniendo en cuenta que esta era el "foco de las conspiraciones [...] que el comercio, único sostén de la provincia, ha sido reducido...”. Posteriormente, fue Arica la que en ejercicio de su soberanía pedía formar un departamento con las provincias de Moquegua y Tarapacá con independencia absoluta de Arequipa y de los demás departamentos del norte. Continuaron luego Moquegua y Locumba. Estas declaratorias fueron elevadas al congreso de Sicuani y fue Santa Cruz el que llevó a cabo dicha aspiración con la creación de la Confederación. Su posición era que el Perú no podía subsistir sin Bolivia y esta, a su vez, sin el Perú (Baldivia, 1919, p. 50-60). ${ }^{4}$ Ya desde 1826, durante el gobierno de Sucre, se propuso al Perú el tratado en Chuquisaca, en el cual se establecía que Bolivia cedería dos

4 No es casual que las quejas más enérgicas proviniesen de Arequipa aún después de finalizada la Confederación, pues durante el gobierno de Castilla, la ruta Arica-Tacna-Bolivia favorecía la prosperidad de algunos departamentos en desmedro de otros. Véase el trabajo de Jaime Rosenblitt en este mismo número. 
de sus provincias a cambio de Arica y Tarapacá, además de pagar la mitad de la deuda extranjera del Bajo Perú, tratado que no fue ratificado por el Gobierno peruano. Por esa razón, la necesidad de activar un puerto boliviano era de singular importancia y con esa idea se buscó reactivar el puerto de Cobija. Pero dicho puerto tenía grandes desventajas, por un lado, escasa población, carecía de agua fresca y estaba a una distancia muy grande de las principales ciudades bolivianas (Pentland, 1975, pp. 107-108).

\section{La legislación comercial entre Perú, Bolivia y Chile}

La situación impositiva dificultó las relaciones mercantiles entre Bolivia y Perú durante 1826 y 1836, debido a la cantidad de decretos, leyes y tratados políticos-comerciales que se llevaron a cabo entre ambos países. Luego de los años convulsionados por las guerras de la independencia, las relaciones de comercio exterior de Bolivia estuvieron divididas entre los puertos del Perú y los de Buenos Aires. Según el informe de Pentland (cónsul británico en Bolivia), en 1826 el Congreso Constituyente impuso un derecho del $40 \%$ a todas las mercancías provenientes de los países sudamericanos que no hubieran reconocido la independencia de Bolivia. Esta ley detuvo de manera significativa el comercio con la ciudad bonaerense, debido a los conflictos suscitados con el gobierno

204 argentino por cuestiones limítrofes y acrecentó el comercio por el Pacífico, en especial por Arica (Pentland, 1975, p. 107; Aillón, 2007, p. 75). El único puerto boliviano en el Pacífico era Cobija (anteriormente denominado La Mar), el cual estaba mucho más lejos de la ciudad de La Paz, centro de la economía boliviana, por lo que las mayores transacciones mercantiles se realizaban a través del puerto de Arica y eso influyó en la relación mercantil entre La Paz y el puerto. La 
Paz era el departamento con mayor cantidad de ingresos. Por un lado, era el más poblado y esa población era indígena, las dos fuentes más importantes de ingreso eran el tributo con un $43 \%$ del total y el comercio que se hacía principalmente por el puerto de Arica. De ahí que muchos comerciantes paceńos se opusieran a la exclusividad de Cobija (Cajías, 1975, p. 222).

El puerto de Arica estaba dentro de la jurisdicción del Perú, pero al ser usufructuado por Bolivia, la legislación debía discernir si las mercancías iban a un país u otro. Así, en 1825, todos los artículos extranjeros pagaban derechos de importación incluso los que iban a Bolivia; en 1826, se estableció el pago del $6 \%$ a todas las mercaderías que se internasen tanto en las provincias del Perú como en Bolivia, pero muchas mercancías estaban en tránsito hacia dicho país y estas debían pagar menos. Fue así que en 1830 se rebajaron a la mitad los derechos sobre mercancías en tránsito hacia Bolivia que entraban en dicho puerto peruano, aunque algunos fueron gravados con un $15 \%$ y otros que estaban prohibidos ingresar al Perú fueron permitidos en tránsito a Bolivia. Durante las conferencias de Desaguadero, que se realizaron con el objeto de sellar la paz entre Santa Cruz y Gamarra, se concedió el tránsito de mercancías por Arica a Bolivia mediante el pago del $2 \%$ de las mercaderías en tránsito. ${ }^{5}$

Según Mariano Felipe Paz Soldán, esto debió ser ventajoso para Bolivia. Sin embargo, el gobierno boliviano lo veía como una hostilidad hacia el puerto de Cobija. Era una con-

5 En las Conferencias de Desaguadero, que se iniciaron el 15 de diciembre de 1830, Santa Cruz pidió para Bolivia el puerto de Arica, pero esto fue rechazado por Gamarra (Basadre, 2002, p. 192). 
tradicción que Bolivia no se contentara con la rebaja de aranceles por Arica. Esto estaba en relación directa con la pugna interna entre el comercio asentado en La Paz, que quería tener facilidades plenas para comerciar con Arica y el comercio que deseaba utilizar exclusivamente Cobija para la totalidad del comercio boliviano. Según Paz Soldán, Cobija era inviable frente a Arica, al menos en cuanto a la zona norte de Bolivia. Geográficamente tenía razón, pero políticamente se entiende que si Bolivia quería promover Cobija, le convenía canalizar todo su comercio por este puerto. Dice Mariano Felipe Paz Soldán:

Estaban tan alucinados con la grandeza del puerto de Cobija que el Ministro de Hacienda en su memoria a la Asamblea de 1832 dijo que con la creación del puerto de Cobija quedaba de hecho cerrado el puerto de Arica para el comercio con Bolivia, y exclamaba, sobre todo Bolivia ya es independiente del Perú: antes estábamos sujetos a tan gravosa y humillante servidumbre. (1878, p. 8).

Fue así que en 1832 una asamblea en Bolivia declaró al puerto La Mar (Cobija) completamente franco y libre de todo derecho nacional y autorizó al ejecutivo construir caminos y facilitar las vías de comunicación. En 1833 y 1834 hubo otros decretos con la intención de limitar el contrabando que de alguna manera provocaban estos tratados, dado que era complejo determinar si el origen de las mercancías era de Bolivia o del Perú, o si estaban en tránsito y para dónde iban.

El problema era que los paceños preferían el puerto de Arica por donde ingresaban productos importados tanto de $\mathrm{Eu}$ ropa como de los puertos aledaños. Como lo hace notar el profesor Cajías: "Arica era necesaria para Bolivia y a la vez estaba en constante contradicción y competencia con el úni- 
co puerto de Bolivia: Cobija. De esto se aprovechó el gobierno peruano para poner subidas imposiciones..." y agrega "si todo el comercio por la vía de Arica se hubiera hecho por el puerto de Cobija, este se habría desarrollado mucho más" (Cajías Bd/Fol 1254). Cajías sostiene, a diferencia de Mariano Felipe Paz Soldán, que el Perú durante los ańos de la Confederación llegó a cobrar por las mercaderías importadas entre un 20, 30 y hasta un 40\% según el valor de las mismas, mientras que por Cobija se pagaba un 5\% (1975, p. 289).

Lo cierto es que mientras estos dos países determinaban cómo establecer el comercio y el pago de aranceles, entre ambos, desde 1830, los extranjeros que aparecieron en los circuitos mercantiles del Pacífico, instalados en el puerto de Valparaíso, fueron los que se beneficiaron con los depósitos francos de bajo costo en dicho puerto establecidos por el ministro Rengifo a dos reales cada seis meses por bulto de dos quintales de peso bruto (Collier, 1999, p. 64; Serrano, 2013, p. 44). A diferencia de ello, en el Callao debido a la política de exclusividad que se imponía durante el gobierno de Gamarra desde 1828 se aplicaron altos aranceles aduaneros (del $80 \%$ ) a las mercancías extranjeras que llegaban al país. Esto no significó que dicha ley se cumpliera a cabalidad ni detuvo el comercio. Existen referencias concretas, por ejemplo, la firma Alsop y Wetmore en 1828 ingresó al Callao en el bergantín Segundo Ayacucho, procedente de Arica, sidras y vinos de Burdeos, que estaban prohibidos, además de azogue, sebo harina, telas varias, quinquillería y sal (AGN Lima, Aduanas, Embarcaciones procedentes Mares del Sur 1821-1828).

En 1832, el Callao se convirtió también en puerto de depósito, lo cual deterioró las relaciones mercantiles entre Perú y Chile, con una legislación que aumentaba los aranceles de la 
harina y el trigo chilenos. En respuesta, el presidente chileno Prieto decidió imponer un impuesto de tres pesos por arroba al azúcar y chancaca peruanos (Serrano, 2003, p. 120).

Existió además un tratado de comercio entre Chile y Perú de 1835 , considerado por algunos autores como la causa de la guerra, dado que beneficiaba a los terratenientes azucareros "proteccionistas" del norte (Gootemberg, 1997, p. 85). Rosenblitt, por su parte, sostiene que si bien la política caudillista del Perú incentivaba el nacionalismo, el librecambismo de Santa Cruz permitió al puerto de Arica aprovechar las ventajas y alcanzar el nivel de los puertos del Callao, Valparaíso o Guayaquil (Serrano, 2013, pp. 128-132). Lo cierto es que, como hacen notar dichos autores, el tratado fue realizado durante el interregno de Salaverry, cuyo gobierno se consideraba ilegal y Chile no estaba dispuesto a ratificar un tratado que no tenía seguridad de ser cumplido.

\section{La Confederación Peruano-Boliviana y la aduana común}

La Confederación Peruano-Boliviana fue proclamada el 28 de octubre de 1836 antes de la división del Perú en dos estados (17 de marzo el Estado Sur Peruano y el 11 de agosto el Estado Nor Peruano) con el auspicio de Andrés de Santa

208 Cruz. Según el reglamento de comercio del Estado Sur Peruano que estableció Santa Cruz, se declaró puerto mayor a Arica e Islay (puerto de ingreso y salida de mercancías procedentes de Arequipa) y puertos menores a las caletas intermedias. Estos eran Sama, Cocotea, Quilca, Pisagua y Mejillones, por los cuales se podían ingresar productos naturales libres de derecho. 
Santa Cruz se enfrentó a la competencia comercial de Chile, que decretó que el puerto de Arica se convirtiera en puerto de depósito y que se construyeran almacenes para tal fin. En ese momento, se estableció que los derechos de almacenaje fueran de 2 reales mensuales por bulto, decreto que más tarde modificó Luis José Orbegoso por considerarlo oneroso para los comerciantes (De Quiroz, 1841, t. 5, pp. 288, 258). En mayo de 1836 se reglamentó el pago de 2 pesos la fanega de trigo y 5 y 3 pesos $2 / 3$ de reales el saco de harina que ingresara desde Chile, además de pagar una fianza correspondiente al doble de lo que debían. En setiembre del mismo año se decretó la libertad de comerciar con todas las naciones: "Serán admitidas en los puertos de Bolivia y de los Estados Sud y Nor Peruanos todas las banderas mercantes incluso la espańola" (De Quiroz y Nieto, 1841, t. 5, p. 364). De esta manera, se abría el comercio libre de los puertos del Pacífico y entraba en competencia con el puerto de Valparaíso. La diferencia sustancial entre el establecimiento de puerto franco en Arica y en Valparaíso era que en Arica el derecho de almacenaje costaba 2 reales mensuales por cada bulto, mientras que en Valparaíso se pagaba la misma cantidad cada seis meses (Serrano del Pozo, 2013, p. 44), lo que prueba que dicho puerto daba mayores beneficios y por esa razón era preferido por los extranjeros que se establecieron en él.

En 1836, se consideraba que las rentas de la Aduana de Arica habían disminuido por el contrabando y por la facilidad de introducir mercancías a este Estado con guías falsas para Bolivia sin pagar otro derecho que el de tránsito. Por esa razón, la junta de Hacienda reunida en Arequipa decretó el establecimiento de una aduana común para Bolivia y el Estado Sur Peruano con empleados nombrados por los dos gobiernos y que cada uno de los Estados debía percibir la mitad de 
las rentas. Se decretó que se cobraría un solo derecho por los efectos importados o exportados por el puerto de Arica de acuerdo con el arancel vigente (Periódico El Estado Sur Peruano, 25 de marzo de 1833, 00128). Santa Cruz cifraba sus esperanzas en la aduana común, porque la aduana de La Paz tan solo recaudaba 87.000 pesos cada semestre, debido a la coca de las yungas que producían unos 70.000 pesos y la aduana de Arica por sí sola no producía sino 15.000 pesos, a lo cual decía: "Aun cuando Oruro y Cochabamba que son plazas de un mercado muy inferior al de La Paz produjeran otro tanto, se debe creer que tales Aduanas, incluso los derechos de alcabala de aguardientes y otros frutos peruanos, no nos dan en Bolivia sino 45.000 pesos en cada semestre" (Querejazu Calvo, 1996, p. 138).

Si comparamos tan solo lo ingresado en los dos años y medio que duró la aduana común de Arica y lo ingresado por Cobija, la diferencia es sustancial. Arica era indispensable para el mantenimiento de los gastos del ejército, como veremos más adelante.

La aduana de Arica representaba el 83\% y de acuerdo con la legislación, la mitad le correspondía a Bolivia, es decir, un $41.5 \%$, porcentaje mucho mayor que el $16 \%$ que recibía por Cobija.

\section{Relación entre Arica, Islay, el Callao y Valparaíso durante la Confederación}

Al comparar el puerto de Arica, Islay, Valparaíso y el puerto del Callao para estimar la frecuencia de las conexiones mediante la cuantificación de las embarcaciones procedentes de uno y otro puerto podemos tener una idea de la intensidad 


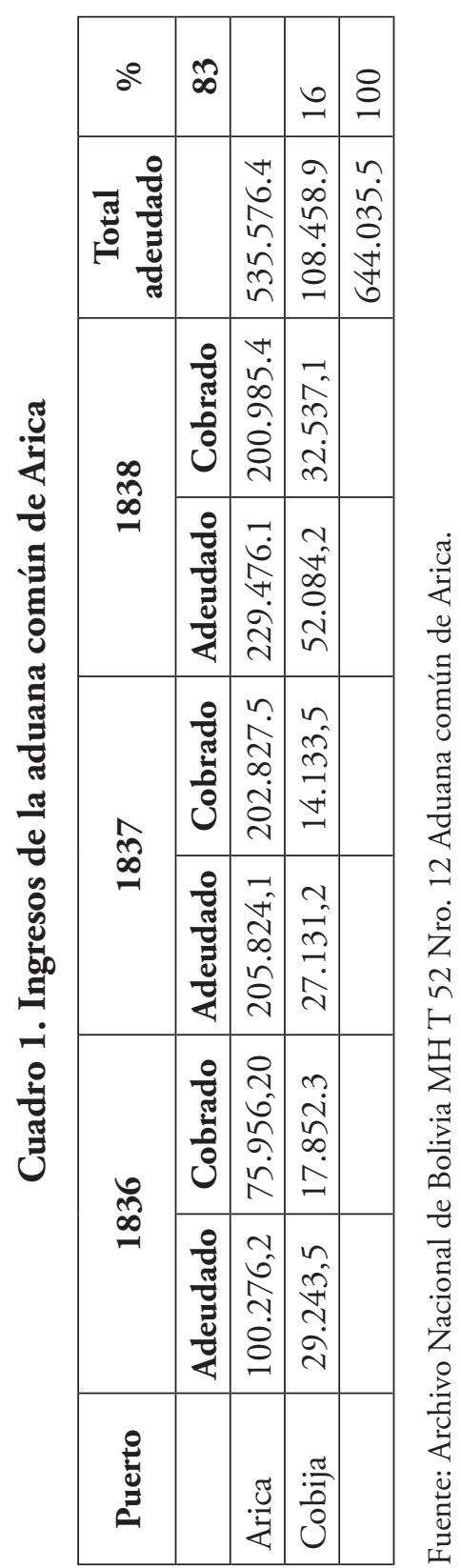


de las relaciones económicas y los contactos entre dichos puertos.

Cuadro 2. Entradas de embarcaciones al Callao procedentes de Valparaíso y de otros puertos del sur andino

\begin{tabular}{|c|c|c|c|c|}
\hline Años & Valparaíso & $\begin{array}{c}\text { Valparaíso, } \\
\text { Arica y otros } \\
\text { puertos }^{\mathbf{6}}\end{array}$ & Arica & $\begin{array}{c}\text { Arica y otros } \\
\text { puertos }\end{array}$ \\
\hline 1832 & 17 & 28 & 2 & 11 \\
\hline 1833 & 22 & 27 & 3 & 7 \\
\hline 1834 & 36 & 14 & 10 & 10 \\
\hline 1835 & 36 & 24 & 7 & 6 \\
\hline 1836 & 23 & 15 & 3 & 7 \\
\hline 1837 & 34 & 13 & 15 & 27 \\
\hline 1838 & 30 & 22 & 9 & 13 \\
\hline 1839 & 53 & 26 & 4 & 10 \\
\hline & 251 & 169 & 53 & 91 \\
\hline
\end{tabular}

Fuente: Capitanía de puerto del Callao - Movimiento marítimo.

Los cuadros 2 y 3 evidencian que la conexión entre Valparaíso y Callao siguió siendo la más importante y que hubo más cantidad de embarcaciones procedentes de Valparaíso que ingresaron al Callao (251) que las que salieron de dicho puerto hacia Valparaíso (216). La conexión Valparaíso-Arica y otros

212 puertos de escala fue relevante, 169 llegadas al Callao y 63 con destino a dichos puertos. También es importante cotejar que en 1837, en plena guerra de la Confederación, hubo una

6 Incluye embarcaciones procedentes de puertos europeos como Liverpool, Baltimore, Río de Janeiro, Londres, Burdeos, Cantón, Centro América, Génova, Iquique, puertos intermedios, Cobija y que tocan además Arica e Islay. 
expansión significativa del comercio, por efecto de la libertad de comercio y la actividad mercantil llevada a cabo por los comerciantes extranjeros, tema que veremos más adelante.

\section{Cuadro 3. Salidas de embarcaciones del Callao hacia Valparaíso y otros puertos intermedios}

\begin{tabular}{|c|c|c|c|c|}
\hline Años & Valparaíso & $\begin{array}{c}\text { Valparaíso, } \\
\text { Arica y otros } \\
\text { puertos }\end{array}$ & Arica & $\begin{array}{c}\text { Arica y otros } \\
\text { puertos }\end{array}$ \\
\hline 1832 & 28 & 6 & 1 & 1 \\
\hline 1833 & 22 & 6 & 0 & 7 \\
\hline 1834 & 24 & 16 & 2 & 4 \\
\hline 1835 & 26 & 9 & 0 & 2 \\
\hline 1836 & 20 & 13 & 1 & 3 \\
\hline 1837 & 24 & 5 & 7 & 5 \\
\hline 1838 & 37 & 1 & 3 & 8 \\
\hline 1839 & 35 & 7 & 2 & 4 \\
\hline & 216 & 63 & 16 & 34 \\
\hline
\end{tabular}

Fuente: Capitanía del puerto del Callao - Movimiento marítimo

Las embarcaciones extranjeras, francesas, inglesas, sardas y hamburguesas que ingresaban al Pacífico por el Cabo de Hornos se proveían en los almacenes de Valparaíso a través de comerciantes que tenían también gran presencia en Arica e Islay y seguían luego rumbo hacia el Callao. El circuito del norte hacia el sur llegaba desde California y era controlado

7 Embarcaciones que van además hacia el norte, Huacho, Paita, Talcahuano, Iquique, Estados Unidos, Guayaquil, Lambayeque, además de Valparaíso y Arica. 
por los barcos norteamericanos. De 216 embarcaciones que salieron hacia Valparaíso en dicho período, 60 eran norteamericanas, 13 peruanas y 21 chilenas. También hubo una presencia significativa de embarcaciones inglesas en la región, como lo demuestra el siguiente cuadro 4.

\section{Cuadro 4. Número de buques fondeados en Arica entre}

1835 y 1840

\begin{tabular}{|l|r|r|r|r|r|r|}
\hline Buques & $\mathbf{1 8 3 5}$ & $\mathbf{1 8 3 6}$ & $\mathbf{1 8 3 7}$ & $\mathbf{1 8 3 8}$ & $\mathbf{1 8 3 9}$ & $\mathbf{1 8 4 0}$ \\
\hline Ingleses & 38 & 44 & 67 & 57 & 49 & 71 \\
\hline Franceses & 23 & 14 & 30 & 30 & 29 & 30 \\
\hline Norteamericanos & 10 & 8 & 6 & 14 & 14 & 14 \\
\hline Chilenos & 9 & 10 & 0 & 0 & 8 & 15 \\
\hline Peruanos & 17 & 6 & 8 & 0 & 4 & 28 \\
\hline
\end{tabular}

Fuente: Denegri Luna (1981, t II).

\section{La Aduana de Valparaíso y el comercio durante la Confederación}

En la mayoría de los trabajos realizados sobre la Confederación se ha enfatizado la oposición de Chile y la decisión de Portales de mantener la supremacía en el Pacífico en detrimento del Callao. Serrano (2013) ha demostrado que la rivalidad entre Portales y Santa Cruz no solo fue política, sino

214 también económica. Este último, en su paso por Chile en 1828, veía la necesidad de firmar un acuerdo comercial entre ambas repúblicas, debido a la "necesidad de estrechar las buenas relaciones". Sin embargo, esto no pudo concretarse (Serrano, 2013, pp. 56-57). Posteriormente, en 1835, siendo presidente de Bolivia, en carta escrita al vicepresidente Calvo decía sobre Portales y su ambición respecto a Chile: 
Presumo que Portales se ha figurado que de Chile puede hacer una Inglaterra americana y arrogarse la supremacía marítima para dictar la ley de los buques, aprovechando la escasez de marina que hay en los otros estados (Querejazu Calvo 1996: 215). [En otra carta agregaba]: Volviendo a los chilenos es claro que no aspiran a más que a la superioridad marítima que desaparecerá tan luego que contemos con una fragata respetable. (Querejazu Calvo, 1996, p. 217).

De las cartas de Santa Cruz se desprende que este no veía realmente un peligro en la movilización de los chilenos y consideraba que podía llegar a acuerdos, como lo intentó en agosto de 1836. Veamos lo que le decía a su vicepresidente en esa fecha:

Acabo de aprobar el convenio preliminar de paz que se ha hecho con los chilenos, y que se remite a Ud. [...] Ud. Notará en las concesiones que hacemos síntomas de mucha calma. Lo he creído así de conveniente para evitar una guerra sin objeto y para convencer de nuestros sentimientos muy pacíficos que los emigrados peruanos pretenden desfigurar suponiéndonos aspiraciones a un sistema continental [negritas ańadidas]. (Querejazu Calvo, 1996, p. 184).

Sin embargo, el gobierno chileno no aceptó esta proposición, por el contrario, siguió con su decisión de enfrentarse a Santa Cruz.

Pero, ¿qué impacto tuvo la Confederación en el comercio chileno? ¿Hasta qué punto afectaron la apertura de los otros puertos, como el de Callao y de Arica en Valparaíso, que se veía beneficiado por la legislación chilena como puerto franco desde 1830 y era preferido por los ingleses? En la aduana de Valparaíso se registraron los siguientes derechos pagados por internación y extracción de mercancías. 


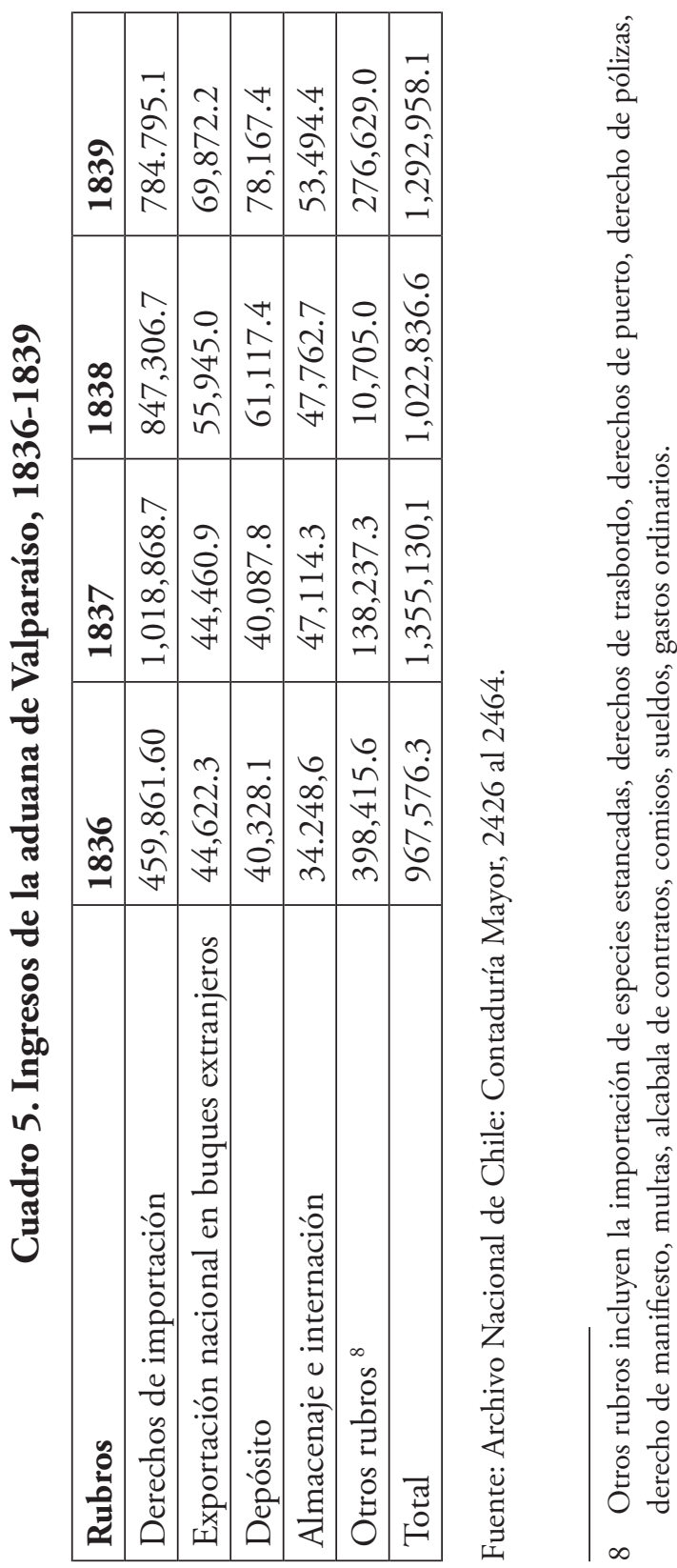


En el gráfico se evidencia más claramente el aumento significativo del $40 \%$ en el comercio entre 1836 y 1837, lo que elevó las rentas de la aduana, estando dicho año en plena guerra de la Confederación. El rubro que más aumentó fue el de derechos de importación, por lo cual deducimos que pudo haber habido una concentración de mercancías en el puerto a la espera de su salida hacia el norte. A la aduana también ingresaba el pago de certificados, es decir, pagarés de aduana que se amortizaban ni bien se cancelaban en la tesorería. Al igual que en el caso de la aduana común de Arica y el Callao, los impuestos de aduana no se cancelaban totalmente, sino que se pagaban en parte, quedando los comerciantes, sean extranjeros o nacionales, siempre endeudados con los gobiernos de turno.

Entonces, ¿hasta qué punto podemos decir que la Confederación afectó el comercio en el Pacífico o redujo las posibilidades al comercio chileno? La decisión de terminar con la Confederación por una supuesta gran competencia pudo haber sido un temor de lo que pasaría en el futuro si se toleraba la unión de Bolivia y el Perú. El comercio, más allá de los conflictos y las posturas políticas, mantuvo su propia dinámica, un engranaje fuertemente lubricado por los intereses comerciales extranjeros, que no dudaban en entrar en negociaciones con los distintos puertos del sur andino. Veamos la información de la Capitanía de Puerto9 de Valparaíso.

9 Lamentablemente, esta información está incompleta, pues no se ha podido encontrar datos de 1838 ni 1839 respecto al puerto de Valparaíso. Tampoco se indica la cantidad ni las mercancías, solo el movimiento de barcos. 

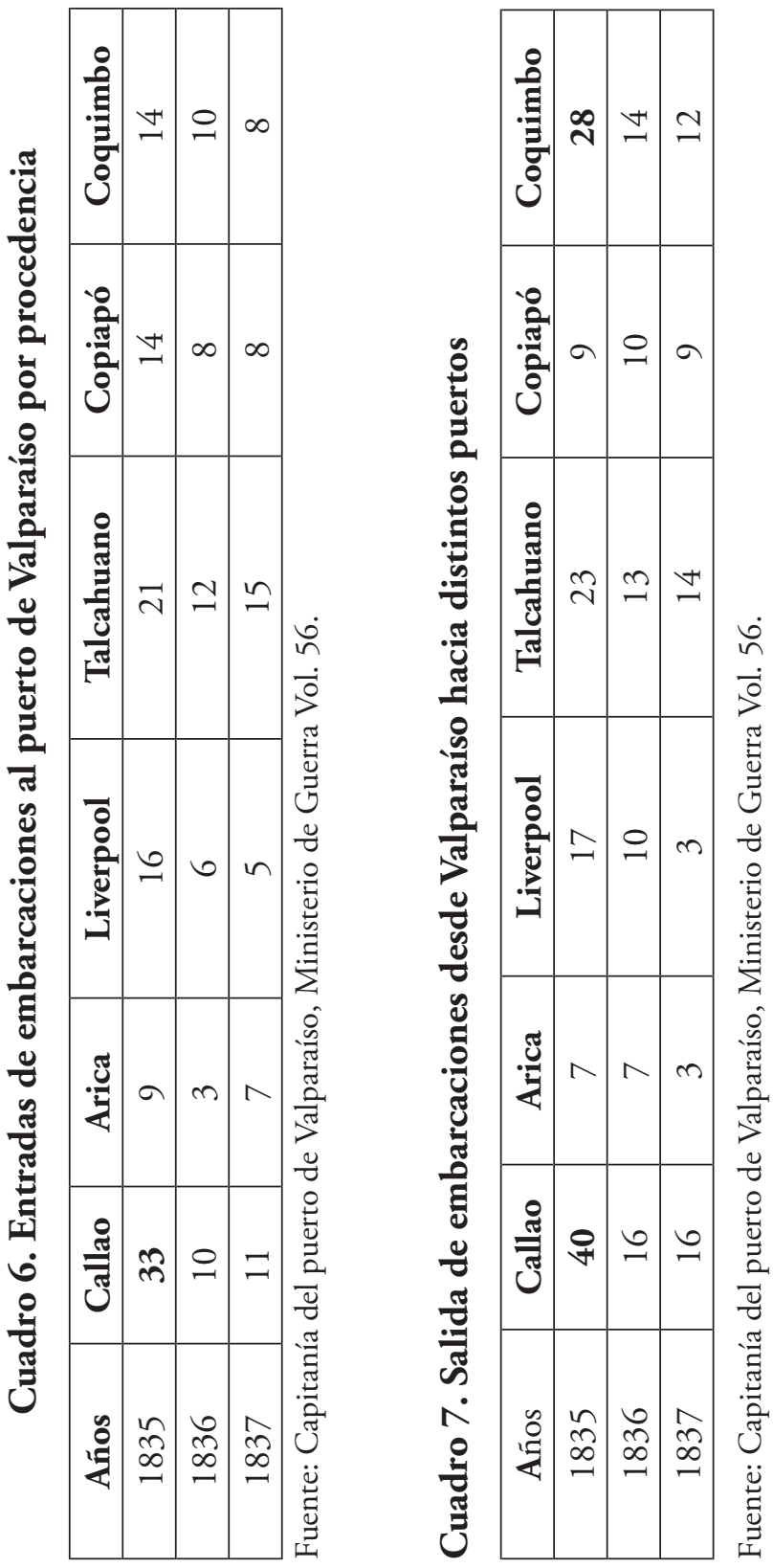
Esta fuente se refiere a la cantidad de embarcaciones que ingresan y salen del puerto. A través de ella vemos que hubo un mayor movimiento en el puerto de Valparaíso en el año 1835 respecto al 1836 . Se evidencia también que durante los tres ańos registrados, la mayor cantidad de embarcaciones que salieron de Valparaíso fueron hacia el Callao (40), mientras que un tanto más reducida fue la relación entre el Callao y Valparaíso (33) y pocas fueron directamente a Arica. Por otro lado, tomando como ejemplo el puerto de Liverpool, el principal proveedor de telas importadas (Mazzeo, 2007, p. 446) que ingresaban a través de casas mercantiles inglesas apostadas en Valparaíso, en 1835 llegaron a dicho puerto mayor cantidad de embarcaciones y también fue mayor la cantidad que salió hacia el Callao. Es posible que Santa Cruz haya conocido este movimiento y por eso, cuando se encontraba en dicho puerto en 1828 , tuvo intenciones de firmar un tratado comercial entre Perú y Chile (Serrano del Pozo, 2013, p. 57).

El segundo puerto en importancia para Valparaíso, luego del Callao, era Talcahuano, de donde procedieron 12 embarcaciones en el año 1836 con madera, trigo y otros productos del país; 13 salieron con víveres, tropas y lastre; en 1837 , aumentaron a 15 las embarcaciones procedentes de dicho puerto y salieron hacia él 14 embarcaciones. Otros puertos significativos fueron Copiapó, del cual se recibía plata piña, y Coquimbo, de donde se embarcaba cobre. Así, se evidencia un subcircuito que incluiría a los puertos de cabotaje que se intercalaban a su vez con el comercio a mayor nivel. Las embarcaciones de todas las naciones que surcaban el Pacífico iban de sur a norte y utilizaban como puertos intermedios, en de Arica, Islay a veces Cobija, hasta llegar al Callao y otros puertos del norte. En cuanto a la salida como la entrada, el 
año 1835 fue más importante que los dos siguientes respecto a la cantidad de embarcaciones

Si comparamos las importaciones llegadas al Perú y Chile en el año 1837 desde distintos países europeos, notamos también que el Callao absorbía mayor cantidad de mercancías que Valparaíso.

\section{Cuadro 8. Importaciones anuales llegadas al Perú y Chi- le desde Europa, Estados Unidos y Asia, 1837}

\begin{tabular}{|l|c|c|c|}
\hline Procedencia & Al Perú & A Chile & $\begin{array}{c}\text { Valor total de } \\
\text { las } \\
\text { importaciones }\end{array}$ \\
\hline Gran Bretaña & $4,500,000$ & $3,000,000$ & $8,000,000$ \\
\hline Francia & 650,000 & 550,000 & $1,200,000$ \\
\hline $\begin{array}{l}\text { Alemania, Rusia, } \\
\text { Holanda y Bélgica }\end{array}$ & 350,000 & 400,000 & 750.000 \\
\hline Italia & 150,000 & 50,000 & 200,000 \\
\hline España & 300.000 & 200,000 & 500,000 \\
\hline Estados Unidos & $1,000,000$ & $1,000,000$ & $2.100,000$ \\
\hline $\begin{array}{l}\text { Cantón y Manila } \\
\text { en buques } \\
\text { norteamericanos }\end{array}$ & 270,000 & 230,000 & \\
\hline & $7.320 .000^{*}$ & 5.930 .000 & $13,250.000$ \\
\hline $\begin{array}{l}* \text { Por casas de } \\
\text { comercio }\end{array}$ & 5.450 .000 & & \\
\hline
\end{tabular}

Fuente: El Eco del Protectorado, No. 138, año 1837.

Dentro del Perú, la mayor distribución de dichas importaciones fue hacia el Estado Nor Peruano antes que al Sur Peruano. 
Cuadro 9. Distribución de importaciones

\begin{tabular}{|l|c|c|}
\hline Países & Estado Nor Peruano & Estado Sur Peruano \\
\hline Gran Bretaña & $3,000,000$ & $1,500,000$ \\
\hline Francia & 400,000 & 250,000 \\
\hline Alemania & 275,000 & 75,000 \\
\hline Italia & 100,000 & 50,000 \\
\hline España & 250,000 & 50,000 \\
\hline Estados Unidos & 900,000 & 200,000 \\
\hline Cantón, Manila & 200,000 & 50,000 \\
\hline Total & 5.145 .000 & $2.175,000$ \\
& & $1 / 2$ a Bolivia $)$ \\
\hline
\end{tabular}

Fuente: El Eco del Protectorado, Nro.138, año 1837.

Se calcula que la mitad de lo que llegaba por Arica pasaba al consumo de Bolivia, por la instauración de la aduana común en dicho puerto. No obstante, el Perú seguía siendo el destino final del comercio inglés, debido a que era un mercado mucho más grande que el de Chile. El censo de Chile en 1835 registró 1,010,332 habitantes y 1,439,129 en 1854, mientras que el Perú en 1827 tenía 1,516,693 habitantes y en 1850 eran 2,001,123 millones (Contreras, Gruber y Mazzeo, 2012, p. 15). Por otro lado, no todo lo que ingresaba a Arica era para La Paz, sino que se reexportaba hacia otros puertos, principalmente el Callao, de allí la importancia de controlar dicho puerto. Mientras que La Paz recibía además importantes ingresos de los estados limítrofes y por la recaudación de la coca, su principal producción.

Comparemos ahora los ingresos que ha tenido la aduana principal de La Paz durante un quinquenio en todos los ramos de su administración. 


\begin{tabular}{|c|c|c|c|c|c|c|c|c|c|c|c|c|c|}
\hline تָ & $\begin{array}{l}0 \\
\text { ñ } \\
\hat{\Omega} \\
\sigma \\
=\end{array}$ & $\begin{array}{l}0 \\
\forall \\
\forall \\
\sigma \\
\dot{\sigma} \\
\sigma\end{array}$ & 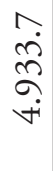 & $\begin{array}{l}0 \\
\infty \\
0 \\
0 \\
0\end{array}$ & 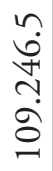 & 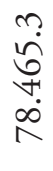 & 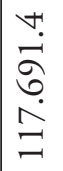 & & $\begin{array}{l}0 \\
\bar{\sigma} \\
\text { m } \\
\text { nn }\end{array}$ & 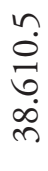 & $\begin{array}{l}\sim \\
\stackrel{+}{*} \\
\stackrel{H}{*}\end{array}$ & 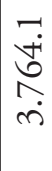 & 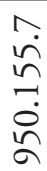 \\
\hline $\begin{array}{l}\hat{\infty} \\
\infty\end{array}$ & 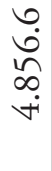 & 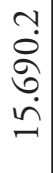 & $\begin{array}{l}\text { ○े } \\
\stackrel{+}{ } \\
\infty\end{array}$ & 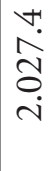 & $\begin{array}{l}\stackrel{+}{+} \\
\stackrel{+}{ } \\
\infty \\
\dot{\sim} \\
\stackrel{\sim}{*}\end{array}$ & $\begin{array}{l}0 \\
2 \\
\infty \\
0 \\
0 \\
0\end{array}$ & 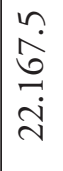 & & 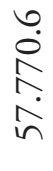 & 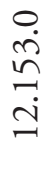 & 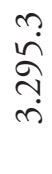 & ڤ્ఠ & $\begin{array}{l}\infty \\
\infty \\
\stackrel{0}{ } \\
\sim \\
\sim \\
\sim\end{array}$ \\
\hline $\begin{array}{l}0 \\
\infty \\
\infty\end{array}$ & $\stackrel{\overbrace{}}{\vartheta}$ & 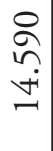 & 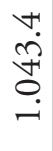 & テَ- & 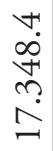 & 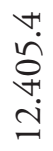 & $\begin{array}{l}n \\
\sim \\
\infty \\
\infty \\
\infty \\
\infty\end{array}$ & & 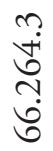 & $\begin{array}{l}\stackrel{\sim}{\sim} \\
\stackrel{\infty}{\infty} \\
\infty \\
\end{array}$ & $\begin{array}{l}\stackrel{0}{\Omega} \\
\stackrel{\text { }}{\sim}\end{array}$ & $\underset{\sigma}{\sigma}$ & 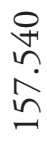 \\
\hline $\begin{array}{l}\hat{n} \\
\hat{\infty} \\
-\end{array}$ & 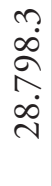 & $\frac{\widetilde{\Xi}}{N}$ & $\begin{array}{l}サ \\
\stackrel{+}{0} \\
\text { ஜ }\end{array}$ & $\begin{array}{l}\forall \\
\text { rn } \\
\text { ñ }\end{array}$ & 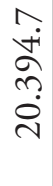 & $\begin{array}{l}\stackrel{0}{\infty} \\
\stackrel{+}{+} \\
\infty \\
\stackrel{\sim}{\sigma}\end{array}$ & 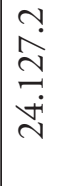 & & $\begin{array}{l}0 \\
\hat{N} \\
0 \\
0 \\
0\end{array}$ & $\begin{array}{l}\stackrel{0}{\sim} \\
\stackrel{\sim}{n} \\
\sim\end{array}$ & $\begin{array}{l}\vec{\infty} \\
\stackrel{\infty}{*} \\
\dot{\sim}\end{array}$ & $\stackrel{n}{\tilde{r}}$ & 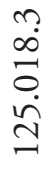 \\
\hline $\begin{array}{l} \pm \\
\infty \\
\infty\end{array}$ & 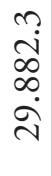 & $\begin{array}{l}\infty \\
\infty \\
0 \\
\text { ஸे } \\
\text { ปे }\end{array}$ & $\begin{array}{l}\hat{\infty} \\
\stackrel{\infty}{\circ} \\
\stackrel{\sigma}{-}\end{array}$ & 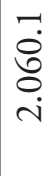 & $\begin{array}{l}\stackrel{\sim}{\sim} \\
\stackrel{\sim}{N} \\
\stackrel{\sim}{\sim}\end{array}$ & $\begin{array}{l}\text { ?a } \\
\stackrel{\rho}{\circ} \\
\stackrel{\infty}{\infty}\end{array}$ & 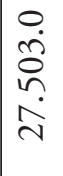 & & $\begin{array}{l}\stackrel{0}{\mathfrak{d}} \\
\stackrel{+}{t} \\
\stackrel{\infty}{-}\end{array}$ & $\underset{\sim}{\stackrel{\sim}{\sim}}$ & 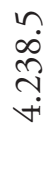 & $\stackrel{n}{\Omega}$ & \begin{tabular}{l} 
?a \\
\multirow{1}{*}{} \\
$\stackrel{\sim}{\sim}$
\end{tabular} \\
\hline $\begin{array}{l}n \\
\infty \\
\infty\end{array}$ & 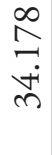 & 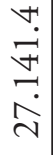 & $\underset{\infty}{\overparen{0}}$ & $\begin{array}{l}n \\
\text { ñ } \\
\text { n }\end{array}$ & 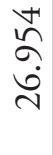 & 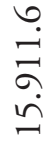 & 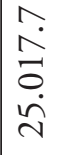 & & 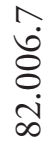 & 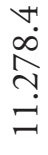 & $\begin{array}{l}\stackrel{\forall}{~} \\
\stackrel{\sim}{F} \\
\dot{\sim}\end{array}$ & $\frac{n}{a}$ & 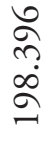 \\
\hline $\begin{array}{l}\text { 을 } \\
\text { 를 }\end{array}$ & 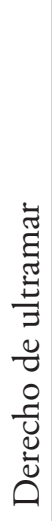 & 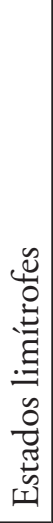 & 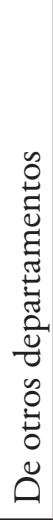 & 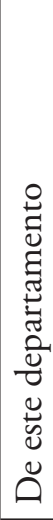 & 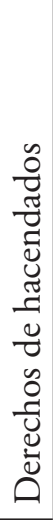 & 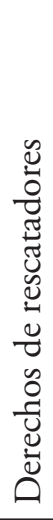 & 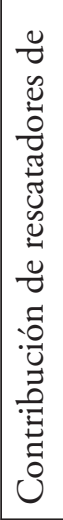 & 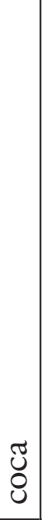 & 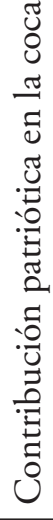 & 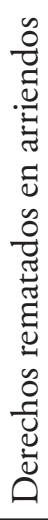 & 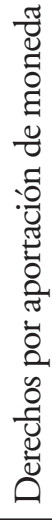 & 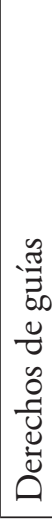 & تีّ \\
\hline
\end{tabular}


Si bien la Paz recibía importantes derechos de ultramar, hubo una baja significativa en el año 1835 y también en los años de la Confederación 1836 y 1837 (AN Bolivia Sucre MH 67-13 1838). Pensemos entonces que La Paz fue la más afectada por la Confederación comparada con Chile y el Perú.

\section{El circuito del comercio entre Islay, Arica, Valparaíso y el Callao}

Las embarcaciones que llegaban a Islay procedían de Valparaíso, Iquique y Arica con salitre, efectos de Europa, cacao, tamarindo, frutos de Chile y pasajeros, como el cónsul de Buenos Aires, José Marcó del Pont, conducido en la fragata francesa Adrianne (El Republicano de Arequipa, 1836, t. 11). Partían generalmente hacia el Callao con efectos de Europa, efectos de Chile y maderas, y caudales que remitían a Valparaíso y Liverpool para la compra de mercancías. De esta manera, vemos un subcircuito desde el puerto de Islay que conectaba Arequipa con los puertos de Valparaíso, Arica y el Callao, a través de comerciantes extranjeros que operaban en los cuatro puertos. Es el caso de la firma Tayleur y Mc Laughlin y Cía.; Gibbs, Crawley y Cía.; Juan Moens y Cristóbal Guillermo Schutte, entre otros. Estos comerciantes pagaron por derechos de internación y de exportación, generalmente plata extraída por el puerto de Islay, las siguientes cantidades que se muestran a continuación. 


\section{Cuadro 11. Pago de derechos de importación y exportación en la aduana de Islay}

\begin{tabular}{|l|r|r|r|}
\hline Comerciante & $\mathbf{1 8 3 7}$ & $\mathbf{1 8 3 8}$ & $\mathbf{1 9 3 9}$ \\
\hline Cristóbal Shutte & 6.769 & 7.931 & 3.179 \\
\hline Juan Moens & 11.033 & 6.644 & 2.372 \\
\hline Gibbs, Crawley y Compañía & 7.943 & 11.839 & 3.000 \\
\hline $\begin{array}{l}\text { Tayleur, Mac Laughlin y } \\
\text { Compañía }\end{array}$ & 13.287 & 6.925 & 7.558 \\
\hline
\end{tabular}

Fuente: ARAR Libro manual del tesoro público de Arequipa 1837 (49) (1838 (52) 1839.

\section{Pago de derechos de importación y exportación en la Aduana de Islay}

De acuerdo con los datos consignados, podríamos decir que a Juan Moens y a Tayleur Mc Laughlin y Cía. les fue muy bien en 1837 y 1839. Pero a Gibbs Crawley y Cía. le fue mejor en 1838, no así en 1839. En cuanto a Juan Moens y Cristóbal Shutte, sus negocios en la región cayeron vertiginosamente en 1839, año en que finalizó la Confederación.

\section{Los comerciantes extranjeros en la aduana común de Arica, Callao y Valparaíso}

Los comerciantes más importantes en las transacciones mercantiles durante la etapa de la Confederación que negociaron mercancías por el puerto de Arica con ingresos y egresos de la aduana común fueron Esteban Casey, José Santiago Basadre, Horacio Bolton, Hugh Gruning y Cía., Pedro Murphy, Hegan Hall y Cía., Luis Stevenson, Tayleur Read y Cía. y Luis Bonded. Muchos de estos comerciantes estaban también asentados en la región Tacna- Arica (J. Rosenblitt, 2013) y también en Valparaíso. 
Estos comerciantes y otros de menor importancia en enero de 1837 debían por derecho de escala un total de 43.772.4 pesos y solo habían pagado 14.442 .4 pesos, es decir, un 33\%. Dentro del grupo, el que más crédito tenía era Esteban Casey. Fue uno de los principales comerciantes que operaba en Bolivia. En 1834, ya se había instalado en Tacna y comenzó a entregar consignaciones de mercancías a los comerciantes bolivianos y, en ocasiones, recurrió a Hugh Grunning de Valparaíso para la obtención de mercancías extranjeras (Rosenblitt, 2013, p. 302).

Los cargamentos que se despacharon por dicha aduana para el consumo del Estado Sur peruano y Bolivia estaban compuestos por efectos ultramarinos, como todo tipo de algodones, lencería de linos, lanas, sedas, aguardiente, ron, coñac, cerveza, champagne, aceites comestibles, mercería y otros artículos.

La firma Tayleur Mc Laughlin y Cía. operaba también en La Paz, donde adeudaba pagarés y pagaba derechos de escala en la aduana común de Arica en el año 1837 (Archivo Nacional de Bolivia, MH 59 10). ${ }^{10}$ Esta firma tenía también representantes en Valparaíso, de donde envió unos 148 bultos de mercaderías para importantes mercaderes de la plaza de Arica. Mc Laughlin había llegado a la región como representante de la firma inglesa en 1830 junto con Hugh Wilson para hacerse cargo de los negocios tanto de Bolivia como del sur del Perú (Rosenblitt, 2013, p. 286).

10 Manifiesto de las existencias en deudas en favor de esta Aduana Común y contra los individuos que se expresan a continuación, respecto del resultado de los pagarés, y pagos hechos en cuenta de todo el presente mes febrero de 1837 . 
Horacio Bolton, otro comerciante importante de la región sur andina, en 1837 extrajo por el puerto de Arica yardas de lona angosta, 100 libras de cacao y 980 yardas de pana y 60 piezas de bayetas de 100 hilos. Este comerciante se había radicado en Tacna, donde operaba con Arica, Arequipa y Bolivia (Witt, 1992, pp. 301-303), y además hacía negocios con Salta (Conti CLADHE IV 2014). En 1836 ingresó por Arica 10 zurrones de añil con 1500 arrobas a 12 reales a través de María Vigil (MH T 52 Nro. 12, 1836); D. E. Appleton extrajo 50 docenas de cuchillos y tenedores, 40 candados, $90 \mathrm{mil}$ tachuelas doradas y 33 arrobas de cominos; Hug Grunning y Cía. también se dedicaba al comercio de paños, quimones y panas. Operaba al crédito y pagaba en dos y tres armadas. En diciembre de 1836 adeudaba aún la segunda y tercera cuota de los productos que había ingresado en el Bergantín Emma, plazos que se cumplieron el 8 de noviembre y el 7 de enero del año siguiente (ANB MH 52: 1836; MH 59, 10: 1837).

Pedro Murphy ingresó ese mismo año (1836) un catre de bronce; Hegan Hall y Cía. ingresó 376 yardas de puntillas, 10 docenas de silletas con asiento de madera y 14 de bejuco, 326 yardas de paño corriente, 198 gruesas de plumas de acero y 356 yardas de género para pantalón. Este comerciante operaba también en Valparaíso y pagaba derechos de almacenaje, al igual que Gibbs Crawley y Cía. Estas mercancías

226 llegaban a dicho puerto a través de otras embarcaciones y luego se distribuían en otras zonas o puertos del Pacífico. De acuerdo con el análisis de las mercancías, no se encuentra que haya habido alguna especialización, todos traían o extraían del puerto los productos comunes extranjeros que se comercializaban desde comienzos de la república, cuando la apertura mercantil benefició a los extranjeros. Otros comerciantes, como José María Valle introdujo 12 docenas 
de cueros, 104 cajones de vino burdalés, 12 cajones de vino blanco graves, 10 barriles de vino tinto y cajones de cońac de Burdeos.

Los comerciantes, José María Pividal, Armando Blondet, Santiago Basadre y Mc Loughling pagaban derechos de importación, arbitrio, consulado, muelle y almacenaje en la aduana común de Arica, que según el reglamento de dicha aduana llegaban a 10 pesos. Entre otras actividades, José Santiago Basadre además de ser comerciante se destacó como primer alcalde de Tacna y fue y uno de los personajes favorable a la Confederación, tenía importantes conexiones en la región, se especializaba en el abastecimiento de manufacturas en los mercados del Alto Perú, comercializaba guano y participó en la obtención de fondos para pagar los sueldos del ejército en Arequipa, mientras que su hermano José María llegó a ocupar la subprefectura de Arica ( Rosenblitt, 2013, pp. 282, 314).

Arica no era donde se encontraba el mercado principal, más bien era Tacna, a donde concurrían los compradores y se "abrían y dividían los cargamentos". Por esa razón, en noviembre de 1836 se resolvió abrir en Tacna una "receptoría" con la facultad de otorgar las guías que debían coincidir con el número de póliza con la que se extrajo la mercancía de los almacenes (MH T 52 Aduana común de Arica, 1836). Lamentablemente, estas guías no existen de acuerdo con las investigaciones realizadas por Rosenblitt en Tacna.

En Valparaíso, otros comerciantes vinculados al comercio con el sur andino fueron Estanislao Lynch, Hegan Hall y Cía., Waddington y Templemann, Alsop y Cía., que introdujeron varios efectos extranjeros, pañuelos, licores, papel, quimones, 
fardos de bayetas, etc. A su vez, Alsop y Cía. figura además en la matrícula del gremio de comercio de Lima, en el año 1837, registrado como de primera clase de almaceneros, junto con Taileur y Cía., Gibbs Crowley y Cía., Hutch Grunnings y Templemann y Bergmann (Consulado de Comercio, dto. 248.645, 14 de mayo de 1836). Waddington asociado con Templemann en Valparaíso fue uno de los comerciantes más destacados de dicha plaza y tuvo vínculos comerciales tanto con Santa Cruz como con Portales. Estaba relacionado además con la firma Alsop y Cía. La firma Waddington ${ }^{11}$ en Valparaíso aparece como Brittain Waddington y Cía. (Serrano del Pozo, 2013, pp. 84-88) y tenía conexiones en Buenos Aires a través de Brittain, que a su vez era el corresponsal de Bergman radicado en el Perú y asociado con Templemann desde 1821. Estos comerciantes habían logrado construir una red mercantil sólida que conectaba el comercio exterior con el comercio interno a través de los puertos y las ciudades del interior del sur andino. Otro grupo familiar y mercantil que conectaba los puertos de Valparaíso con los de Bolivia y las ciudades del norte argentino era la firma Lezica Hnos. Estos también eran proveedores de azogue al gobierno de Santa Cruz (Querejazu Calvo, 1996, p. 209). Alsop aparece asociado con Wetmore en Lima desde 1821 y comercializaba papel, maonas, harina, silletas y azogue con los puertos de Arica, Pisco, Quilca y el Callao (AGN Lima Mares del Sur 228 1821-1827).

11 Waddington asociado a Green importaron armamento para el ejército de San Martín y recibieron de la administración de la aduana la suma de 2000 pesos como parte de la contrata por 4.910 pesos que importaba la totalidad del cargamento ingresado en el bergantín inglés Sir Francis Baring (Archivo Militar del Perú, 24/5/1822). 


\section{Contratos específicos para el sostenimiento del ejército}

Uno de los negocios más importantes durante la guerra fue el aprovisionamiento del ejército boliviano a través de la aduana común, cuya firma principal para la provisión de armas fue la casa comercial Hegan y Cía. En 1836 se hizo una contrata para la compra de 1.020 fusiles ingleses a $91 \frac{1}{2}$ pesos cada uno, cuyo pago se haría con la mitad de los derechos de toda clase que resultaran por los despachos hechos por la aduana de Arica (ALP, MH 52 Nro 12). Anteriormente, Santa Cruz (1832) había concesionado a la casa Lezica Hnos., en Valparaíso, sables y corazas para el ejército, y 4 cañones comprados al comerciante francés Pedro Hubert. Al año siguiente, 1833, el gobernador del litoral envió al ejército 500 fusiles ingleses contratados por el comerciante Lafayet y comprados en las casas comerciales de Valparaíso que ingresaron en Cobija (Cajías, 1975, p. 258). En 1836, el comerciante Villamil fue el proveedor de 3000 fusiles que consiguió a un precio muy bajo en Francia, que pudo llegar a 2 pesos por fusil (Querejazu Calvo, 1996, p. 133).

Otras de las necesidades importantes durante la Confederación fue el aprovisionamiento del azogue, dado que las armas se pagaban con pesos fuertes y dependían de Valparaíso para su suministro. En 1837, se realizó una contrata con José María Pividal, quien por medio de Juan María Valle de Tacna compró 288 frascos de azogue que contenían 192 quintales, a 120 pesos al fiado según el detalle del cuadro 12 . 


\section{Cuadro 12. Detalle de la contrata de José María Pidival}

\begin{tabular}{|l|r|}
\hline José María Pividal para 192 quintales a 120 pesos & 23.040 \\
\hline Gastos por comisión de compra 2\% & 4.560 .6 \\
\hline Por flete de Arica a Tacna en 96 cargas a 20 reales & 240 \\
\hline $\begin{array}{l}\text { Por } 50 \text { pesos adelantados al propio por media } \\
\text { paga }\end{array}$ & 50 \\
\hline $\begin{array}{l}\text { Por desembarco y almacenaje a 2 reales por cada } \\
3 \text { frascos }\end{array}$ & $1.926 .61 \frac{1}{2}$ \\
\hline Total & $24.966 .61 \frac{1}{2}$ \\
\hline
\end{tabular}

Fuente: Archivo Nacional de Sucre, MH T 52 Aduana común de Arica 1836.

Pividal compraba los azogues, por medio de Juan María Valle, en una cuenta del Banco Nacional de Potosí, en Valparaíso. Los azogues entraban en Arica y se trasladaban a Tacna hasta la llegada de los fondos para pagar los fletes. Si bien en Londres los azogues se conseguían a 101 pesos el quintal, estaba muy escaso dado que en Europa "había habido una alteración grande con la contrata de Roschil”. De continuar esta dificultad deberían recurrir nuevamente a Huancavelica (MH T 52 Aduana común de Arica 1836).

Otro de los productos importante era la compra de papel y sello, necesarios para la confección de guías y tornaguías para

230 la administración de la aduana de Arica, además de vituallas para el ejército. El comerciante Juan Mas, vecino de la ciudad de la Paz, era uno de los proveedores del ejército. En 1837, firmó un contrato con el ministro de Guerra Juan Braun, el vicepresidente Calvo y el ministro de Hacienda Lara para importar de Francia 2000 plumeros amarillos, 500 encarnados y 700 verdes; dos mil cordones amarillos, 700 cordones verdes y 500 encarnados; 3000 pompones, 3000 pares de 
carrilleras, 2500 de amarillas y 2500 caponas amarillas, 700 verdes y 500 caponas encarnadas, 3000 corbatines, 2500 varas de pańos encarnados, 400 varas de amarillo y 400 de verde, productos que tenían como fin la elaboración de los uniformes de las fuerzas bolivianas. También se le encargó al mismo comerciante la compra de 94 piezas de paño grana a 2.265 pesos; 76 piezas de paño azul de 1.869 yardas, 16 verdes con 394 y 16 amarillos a 398 pesos, total 4921 1/2 yardas a razón de 2 pesos cada una por un total de 9.893 pesos.

Otros productos necesarios para el ejército eran corbatines, caponas, carrilleras, cornetas, pares de charreteras, cajas de guerra de latón y granadas de cobre bruñido, los cuales se adquirieron por un total de 28.522 pesos. El pago no se hacía en efectivo, si no en 4 armadas: la primera de 7.000 el día de la entrega y las tres restantes en dos meses hasta la total cancelación. El dinero saldría del tesoro de la Paz, al igual que todos los demás gastos de guerra (A La Paz, Prefectura, 26 enero de 1837).

En una ocasión, el ciudadano Luis Lavardén se presentó al comandante del departamento con unas 700 camisas para la tropa, al precio de 8 reales y medio cada una de acuerdo con una muestra presentada para que ver el tamaño y calidad. El informe explica que en el año 1825 se habían contratado las mismas camisas al igual que la muestra o de tocuyo inglés al precio de ocho reales presentadas por don José Castaños del comercio de La Paz. Pero si no había otro empresario que mejore la propuesta debían admitirse y abonarse conforme la contrata (A La Paz, Prefectura, Nro. 645).

Otros comerciantes de La Paz se adelantaban a los pedidos del gobierno y presentaban sus propuestas con mercancías 
necesarias para el ejército. Fue el caso de Juan Bautista Chenaut, que tenía a la venta 2.073 pares de zapatos de munición de buena calidad para la tropa al precio de 4 y un cuartillo reales al contado. "No hay ejemplo señor prefecto que se hayan vendido zapatos a un precio tan acomodado porque el valor que los ha recibido el estado es de cuatro y tres cuartos cuartillos". Por tal razón, consideraba que fuese aceptada aunque el Estado contaba con 2.850 pares de zapatos para el gasto mensual de la tropa, pero eran necesarios muchos más porque eran dos los batallones sostenidos por el departamento de La Paz, cuyo consumo mensual se acercaba a 1000 pares (A La Paz, Prefectura, 1837).

En 1837, Juan Mas firmó una nueva contrata con el gobierno para el aprovisionamiento del vestuario de parada compuesto por casacas de pańo, pantalones, pares de botines de paño y pantalones de brin y botines de brin, por la cantidad de 4345 de cada una de las especies. El valor de un vestuario completo de parada compuesto por dichos productos era de 15 pesos, por lo que el total de la contrata fue de 65.175 pesos. Esta cantidad se pagaría en abonos de 6 armadas de 3000 pesos, quedando aún a su favor 12.502 pesos 4 reales (A La Paz, Prefectura 11 de febrero de 1837 Dto. 414).

Otras compras para el ejército, como piezas de bayetón lle232 garon del Cusco al precio de 4 y medio reales la vara, por un total de 5.653 pesos. Estos eran de color blanco, amarillo y gris de jerga abatanada y sogas para liar los tercios. El 4 de octubre de 1837 también se compraron 1.000 camisas de tocuyo inglés que se mandaron a trabajar en comisión y se abonarían 7 y medio reales por cada una, de acuerdo con lo siguiente: tres varas de tocuyo compradas a $13 / 4$ reales; hechura 2 reales; cuello, hilo e hilera, total 8 reales; se rebaja 
medio real en cada una (ANL Prefectura, dto.1072). Se entregaron además 5 docenas y 9 camisas de hilo, a razón de 14 pesos la docena, 33 camisas para sargentos también de hilo a razón de 20 pesos que hacen un total de 135.4 pesos. Otro precio interesante que aportan estos documentos de La Paz es el valor de las mulas, cuyo contrato costaba ocho pesos cada una para llevar a Puno el vestuario del batallón segundo de la guardia. En 1838, hubo una nueva propuesta para vender al Estado 2000 pares de zapatos al precio de 4 y medio reales, que ofreció Pascual Galatone (ANL Prefectura, 17 de julio de 1838). Estos productos ingresaban por el puerto de Arica, por lo tanto, era indispensable el control del mismo. La idea de Santa Cruz de generar mayores ingresos por dicha aduana era indispensable para la Confederación.

\section{Conclusiones}

Se han descrito las vicisitudes del comercio en el área del $\mathrm{Pa}$ cifico sur durante la Confederación. Al margen de la competencia de intereses entre Chile y Perú personificados en Santa Cruz y Portales, y los conflictos políticos que se presentaron en la conformación de la Confederación Peruano-Boliviana entre los peruanos, tema que ha sido bastante tratado por la historiografía, considero que el punto de quiebre fue el conflicto generado por el control de los puertos de Arica, Cobija e Islay, indispensables para el aprovisionamiento de las ciudades del sur andino. Estos puertos estaban fuertemente vinculados con Valparaíso y el Callao a través de los comerciantes extranjeros asentados en dicho puerto, que tenían importantes conexiones con Tacna, Arequipa y el norte argentino. Dichos comerciantes mantuvieron, además, sus relaciones mercantiles con el Callao, puerto que a pesar de la guerra siguió vinculado con Valparaíso si tenemos en cuenta 
la cantidad de embarcaciones que llegaron a dicho puerto. Solo en épocas de bloqueo se habilitaron, para el ingreso de mercancías, el puerto de Chorrillos, Ancón, Pucusana, Lachira y Chancay en el departamento de Lima, en octubre de 1836 (De Quiroz y Nieto, t. 5, p. 400).

Al ser Arica un puerto peruano usufructuado por Bolivia, exigió una legislación comercial detallada y compleja con el objetivo de determinar qué mercancías iban a uno y otro país. Por tal razón, cuando se estableció la Confederación, se decidió la creación de una aduana común, de manera que se pagaba un solo arancel y se distribuían los beneficios entre Bolivia y el Estado Sur Peruano. Sin embargo, los ingresos por esta aduana nunca llegaron a ser tan importantes como los del Estado Nor Peruano, que absorbía la mayor cantidad de importaciones procedentes de Europa, vía Valparaíso y los puertos intermedios de Arica e Islay. Cobija no tuvo mayor representatividad durante la Confederación y las mercancías que antes llegaban por ese puerto para abastecer el norte argentino se realizó por la vía de Buenos Aires. La documentación de aduana consultada, ya sea de Bolivia o de Valparaíso, indica que se operaba a crédito y solo en ocasiones se pedía que algunos impuestos fueran pagados en efectivo.

La decisión de establecer Arica e Islay como puertos fran-

234 cos durante la Confederación evidentemente provocó mayor competencia con Valparaíso, pero esto no significó una disminución del comercio por Valparaíso, al contrario, benefició a los comerciantes extranjeros que ampliaron sus zonas de ingreso, dado que eran los mismos que operaban en uno u otro puerto. Tampoco se evidencia que la aduana de Arica haya afectado la relación mercantil entre Valparaíso y el Callao, pues la vinculación de ambos puertos continuó con 
algunas dificultades propias de las acciones de guerra, pero no se detuvo.

El conflicto suscitado entre Arica y el puerto de Cobija generó una gran competencia por parte de los intereses que promovieron los comerciantes paceños, a quienes les convenía más la conexión con Arica, y aquellos que querían potenciar el puerto de Cobija, pero no significó una desarticulación del comercio tradicional. La aduana de La Paz evidenció una fuerte retracción durante la Confederación, pues fue más importante la recaudación patriota que la de los derechos de ultramar. Valparaíso y el Callao continuaron siendo los dos puertos de mayor importancia en el Pacífico y así lo vieron los comerciantes extranjeros, que no dudaron en aprovechar la coyuntura para aprovisionar a los ejércitos durante la guerra con sus mercancías traídas de Europa.

Al comparar Arica con el Callao y Valparaíso, vemos que la conexión Arica-Callao fue más importante que la conexión Callao-Arica, como lo había sido en el decenio anterior entre 1818 y 1828, debido a que el circuito por el Pacífico se realizaba de sur a norte. Y de norte a sur era controlado prácticamente por las embarcaciones norteamericanas e inglesas.

Arica continuó siendo el puerto principal de tránsito en la ruta comercial, por lo tanto, pese al conflicto político se mantuvo una unidad económica por la red de clientes y el control que llevaron a cabo los comerciantes extranjeros que operaban en la región. Estos fueron los verdaderos beneficiarios de la Confederación y los que se instalaron en Valparaíso, porque les brindaba mayores beneficios arancelarios. Ellos estuvieron al margen de las cuestiones políticas y más bien supieron sacar ventajas de las necesidades y proveían a 
los ejércitos durante la guerra. Los puertos intermedios jugaron un papel significativo en esta relación mercantil en el Pacífico, relación que venía de mucho tiempo atrás y que en ese período permitió una mayor expansión del comercio internacional. Al disolverse la Confederación con la caída de Santa Cruz, el puerto de Cobija se convirtió en el principal ingreso a Bolivia y su conexión con el sur andino. ${ }^{12}$ Mientras que Arica mantuvo su posición intermedia, de tránsito en el gran comercio entre Valparaíso y el Callao, lo que le dio preeminencia en el Pacífico.

Recibido: 18 de junio de 2017

Aprobado: 05 de abril de 2018

\section{Fuentes de archivos}

Archivo Nacional de Bolivia, Sucre

Archivo de La Paz

Archivo Nacional de Chile

- Capitanía de Puerto

- Contaduría Mayor 1ra. y 2da. Serie

Biblioteca Nacional de Chile

236 - Periódico el Araucano

Biblioteca Nacional de Bolivia, La Paz

Archivo General de la Nación, Lima

- Documentos de Aduana, Consulado

12 Véase en este número el trabajo de Viviana Conti. 
Archivo de La Marina

- Capitanía de Puerto del Callao

Instituto Riva Agüero (PUCP), Lima

- Periódico El Eco del Protectorado

\section{Bibliografía}

Aillon, E.

(2009) En torno a la desestructuración del espacio colonial andino: Bolivia 1825-1850. Del Altiplano al desierto (pp. 41-81). Valparaíso: Pontificia Universidad de Valparaíso.

Baldivia, J. M.

(1919) Tacna y Arica, Cobija. (2ªrte) (2a. ed.). La Paz.

Basadre, J.

(1999) Historia de la República del Perú, 1822-1933 (8ª ed.). Lima: Universidad Ricardo Palma.

Cajias, F.

(1975) La provincia de Atacama (1825-1842). La Paz: Instituto Boliviano de Cultura.

Cavieres, E. (Ed.)

(2007) Del altiplano al desierto, construcción de espacios y gestación de un conflicto. Valparaíso: Ediciones Universitarias de Valparaíso Pontificia Universidad Católica de Valparaíso.

Cavieres, E. (Ed.).

(2007) La construcción de los espacios: significaciones económicas y conflictos nacionales; Bolivia, Chile $\mathrm{y}$ Perú, 1780-1840. En Del Altiplano al desierto (pp. 17-39). Valparaíso: Pontificia Universidad Católica de Valparaíso. 
Collier, S. y Sater, W. E.

(1999) Historia de Chile 1808-1994. Madrid: Cambridge University Press.

Contreras, C. y Cueto, M.

(2000) Historia del Perú contemporáneo, desde las luchas por la independencia hasta el presente. Lima: Pontificia Universidad Católica del Perú, Instituto de Estudios Peruanos, Universidad del Pacífico.

Contreras, C., Gruber, S. y Mazzeo, C.

(2012) Orígenes históricos de la desigualdad en el Perú. Documento de Trabajo No. 328. Lima: Pontificia Universidad Católica del Perú, Departamento de Economía.

De Quiroz, M. S. y Nieto, J. C.

(1841) Colección de leyes y decretos y órdenes en el Perú desde su independencia. Lima, Imprenta de José Masías. tomos 5 y 6 (1836-1839).

Denegri Luna, F.

(1981) Historia maritima del Perú. Vol. 6. La República 1826 a 1851. Lima: Instituto Marítimo del Perú.

Donoso, C. y Rosenblitt, J. (Eds.)

(2009) Guerra, región y nación, La Confederación Perú-Boliviana 1836-1839. Santiago: Centro de Investigaciones Diego Barros Arana, Universidad Andrés Bello, Dirección de Bibliotecas Archivos y Museos.

238 Gootemberg, P.

Caudillos y comerciantes. La formación económica del estado peruano 1820-1860. Cusco: Centro de Estudios Regionales Andinos Bartolomé de las Casas.

Manrique, N.

(1995) Perú y Bolivia, La fraternidad escindida. En Perú - Bolivia forjando la integración. Lima: Fundación Friedrich Ebert. 
Parkerson, P. T.

(1984)

Andrés de Santa Cruz y la Confederación Perú-Boliviana 1835-1839. La Paz: Editorial Juventud.

Paz Soldán, $M$.

El Perú y Bolivia en sus relaciones politico comerciales. Lima: Imprenta La Opinión Nacional.

Pentland, J. B.

(1975) Informe sobre Bolivia. Potosí.

Querejazu Calvo, R.

(1996) Oposición en Bolivia a la Confederación Perú-Boliviana. Sucre, Bolivia.

Roca, J. L.

(2011) Ni con Lima ni con Buenos Aires, la formación de un Estado nacional en Charcas. La Paz, Plural Editores, IFEA.

Rosenblitt, J.

(2013) Centralidad geográfica, marginalidad politica: La región de Tacna-Arica y su comercio, 1778-1841. Santiago, DIBAM, Centro de Investigaciones Diego Barros Arana.

Serrano del Pozo, G.

(2013) 1836-1839 Portales y Santa Cruz, Valparaíso y la Guerra contra la Confederación. Valparaíso: Universidad Andrés Bello, Instituto de Historia, Programa de Estudios, Iberoamericanos, Pontifica Universidad Católica de Valparaíso

Witt, H.

(1992) Un testimonio personal sobre el Perú del siglo XIX, volumen I: 1824-1842. Lima, Banco Mercantil. 
Zapata, A.

(2009) La política peruana y la Confederación Perú-Boliviana. En C. Donoso Rojas y J. Rosenblitt (Eds.), Guerra, región y nación: La confederación Perú-Boliviana, 1836-1839 (pp. 93-116). Santiago, Centro de Investigaciones Diego Barros Arana, Universidad Andrés Bello, Dirección de Bibliotecas Archivos y Museos. 